\title{
¿QUÉ HA SUCEDIDO EN ESTOS 25 AÑOS DE HISTORIA EN LA PASTORAL VOCACIONAL DE LA IGLESIA CATÓLICA?
}

DOI: https://doi.org/10.52039/seminarios.v58i205-206.286

\author{
RAFFAele SACCO \\ EUSEBIO HERNÁNDEZ*
}

\section{PREMISA}

Un Congreso sobre las vocaciones sacerdotales y consagradas en Europa en el umbral del siglo XXI podría parecer algo temerario; por el contrario, ha resultado un acontecimiento de reflexión eclesial y de toma conciencia colectiva sobre uno de los problemas más graves y urgentes para el futuro de la comunidad cristiana.

«Un acto de fe en la acción eficaz y constante de Dios. Un acto de esperanza en el futuro de la Iglesia en Europa. Un gesto de amor al pueblo de Dios en el 'viejo continente', necesitado de personas plenamente dedicadas al anuncio del Evangelio y al servicio de los hermanos». Así definía Juan Pablo II en su mensaje de saludo, el Congreso Europeo «Nuevas vocaciones para una nueva Europa», que tuvo lugar en Roma entre los días 5 y 10 de mayo de 1997.

La asamblea del Congreso había indicado con fuerza la necesidad de emprender una pastoral vocacional coral: «La pastoral vocacional no puede acabarse en iniciativas ocasionales o extraordinarias, sino que debe constituir una de las preocupaciones constantes de la pastoral de la Iglesia local; eso es buscar el esfuerzo coral para superar algunos comportamientos que pueden hacer marcar el paso a la promoción vocacional, convertirla en fatiga ineficaz: como el comportamiento de los poderes, lo provisorio de las iniciativas o todavía peor la expectación fatalista de que la historia resuelva el problema de Europa» (Mensaje a la comunidad eclesial, n. 4).

\section{LA PREPARACIÓN DE UNA NUEVA PASTORAL VOCACIONAL}

\subsection{La Segunda Guerra Mundial y el problema de las vocaciones}

Eran años durísimos. La guerra había implicado a muchas partes del mundo. Poblaciones trastornadas. Familias destruidas. Seminarios y otros institutos de

* Raffaele Sacco, rogacionista, es Vicario provincial, Consejero para la vida religiosa, formación de base y permanente, y Superior delegado del «Centro Internazionale Vocazionale Rogate» (Roma). Mons. Eusebio Hernández es Obispo de la diócesis de Tarazona (Zaragoza). 
formación reducidos a ruinas. Muchos sacerdotes, religiosos, misioneros muertos. El Papa Pío XII miraba al futuro e indicaba un nuevo camino para la reconstrucción: la Pontificia Obra para las Vocaciones Eclesiásticas'.

Publicaron los Estatutos y las normas de aplicación de los Estatutos de la $\mathrm{POVE}^{2}$. La Obra central quedaba constituida como persona moral de Derecho Pontificio ${ }^{3}$ y debía procurar la institución y el incremento de las Obras por las Vocaciones en todas las diócesis, promover el conocimiento del sacerdocio, la oración específica, habitual y constante, y una apropiada y aggiornata acción pastoral; y por consiguiente producir publicaciones, convocar congresos, mantener relaciones con las obras asociadas, recibir relaciones con la actividad desarrollada, sin interferir en el régimen interno de la Obra misma. La Obra central actualizó su programa con discreción y continuidad, manteniendo las relaciones con los pastores de las Diócesis.

La sede de la POVE fue querida por el Papa cerca de la Congregación para la Educación Católica, consciente de la debilidad de tantos lugares pedagógicos (grupos, comunidad, oratorios, escuelas y sobre todo familias) y convencido de que la crisis vocacional era también crisis de propuesta pedagógica y de camino educativo. En realidad cada intervención del Dicasterio en apoyo de la Educación cristiana tenía también su reflexión positiva sobre la vocación. El Concilio había percibido la decisión libre y madura de seguir la vocación como fruto de la educación profunda que había sabido preparar en «buen terreno» a los dones del Espíritu (cf. OT 2-3). Educación actuada en la familia propiamente (LG 11; GS 52) y de forma privilegiada en la escuela católica (GE 3).

Quince años después de la institución de la POVE, el 11 de febrero de 1955, la Congregación de Religiosos, por propia iniciativa pide y obtiene la institución de una Pontificia Obra para las Vocaciones Consagradas, asumiendo como propios los estatutos y las normas ejecutivas de la POVE.

La constitución de una nueva Pontificia Obra para las Vocaciones Religiosas hace tomar conciencia al episcopado de que debe dar una coordinación en la pastoral de las vocaciones de forma unitaria ${ }^{4}$, o sea, erigiendo centros unitarios

1. Cf. AAS 33 (1941) 479; AAS 35 (1943) 369-373.

2. AAS 35 (1943) 369-373.

3. El Motu Proprio Cum nobis de Pío XII, en donde instituye la Pontificia Obra Primaria por las Vocaciones, y los sucesivos Estatutos y Normas ejecutivas, provenientes de la Congregación de Seminarios y de los Institutos de Estudio (cf. AAS 33 [1941] 479; AAS 35 [1943] 369-373) fueron concebidos a la luz de los elementos de derecho existentes de hecho.

4. Tras el Congreso Internacional de 1973, constitutivo de los Centros Nacionales Unitarios para las Vocaciones, desaparece del Anuario Pontificio la Pontificia Obra de las Vocaciones de los Religiosos, dando paso a una única Pontificia Obra Unitaria de los sacerdotes y de los consagrados según el dictamen conciliar de Optatam totius 2 y el respetuoso obsequio al documento del Congreso de los delegados de la Conferencia de Obispos y de Consagrados. El Anuario Pontificio explica en nota: «Por lo cual la mismísima Congregación ha erigido la Pontificia Obra de las Vocaciones sacerdotales (Motu proprio de Pío XII Cum nobis de 4.11.1941), la cual ha recibido mayor impulso y claridad en el Decreto Conciliar Optatam totius, n. 2, del 28 de 
para todas las vocaciones sacerdotales o consagradas: se crearon los Centros Nacionales y Diocesanos únicos para todas las vocaciones. Se presentan procedimientos para disciplinar el «reclutamiento» y se envía personal a tiempo pleno para el cuidado de las vocaciones.

\subsection{El Concilio Vaticano /I}

Por primera vez en la historia un Concilio ecuménico debía ocuparse de pastoral para las vocaciones. Los hechos testimonian la solicitud de los Padres. Al final la materia quedaba distribuida en varios documentos (Lumen Gentium; Christus Dominus; Perfectae Charitatis; Optatam Totius; Dei Verbum; Apostolicam Actuositatem; Ad Gentes; Gaudium et Spes; Presbyterorum Ordinis).

Los Padres del Concilio conocían la situación de desorden pastoral que se había llegado a crear en la pastoral vocacional local. Pusieron orden a la situación pastoral dando tres disposiciones:

1) La Pontificia Obra de las Vocaciones sacerdotales y consagradas debe promover toda la pastoral vocacional (OT 2);

2) El Obispo es el primer responsable de las vocaciones sacerdotales y consagradas (CD 15);

3) Los consagrados tienen el derecho de promover las vocaciones propias dentro de una pastoral de conjunto; observando las normas de la Santa Sede y de las Iglesias particulares (PC 24).

\subsection{La obra de las vocaciones según el Concilio}

El Concilio ${ }^{5}$ recibió la Obra tradicional de las vocaciones «secundum pontificia ad rem documenta» (OT 2), pero de allí profundizó y extendió la misión. En el futuro, por mandatum del Concilio, la Obra de las Vocaciones deberá, de hecho, dirigir y promover toda la actividad pastoral para las vocaciones sacerdotales y consagradas, actuando a varios niveles de las circunscripciones eclesiásticas (diocesanos, regionales, nacionales), bajo la guía de los Pastores locales con la colaboración de todos los responsables, con el uso de todos los

octubre 1965». No obstante la gran solicitud pastoral de los Pontífices por las vocaciones, y de los Padres conciliares, aquellos que han colaborado a la difusión tanto de la Regimini Ecclesiae Universae como de la Pastor bonus han ignorado completamente la existencia de la POVE y de la renovación querida por el Concilio de esta única institución central de la Iglesia para la promoción de las vocaciones sacerdotales y consagradas. La última plenaria de 2001 de la Congregación para la Educación Católica ha resuelto el problema, pidiendo la sustitución de la Pontificia Obra por un Pontificio Consejo para las vocaciones que podría actualizar el mandato del Concilio de organizar adecuadamente la pastoral vocacional para los cinco continentes y sostener y acompañar a las Iglesias en esta tarea tan importante (cf. Archivio Ufficio Vocazioni, Verbale della Plenaria 2001, Voto de Su Em. Card. Somalo E. Martínez, Prefecto de la Congregación para los Institutos de vida consagrada y las Sociedades de vida apostólica).

5. El Concilio profundizó en tema de la vocación en su «objeto», como vocación general y como vocación particular. 
medios necesarios y oportunos, al servicio de todas las vocaciones, para el bien de toda la Iglesia, mirando más allá del límite de diócesis, naciones, familias religiosas, ritos, con particular solicitud hacia aquellos que se encuentran con mayores dificultades. Esta es la renovada Obra de las Vocaciones que el Concilio ha proyectado, teniendo como punto de referencia el mundo de hoy y como horizonte la necesidad de la Iglesia universal. Los Padres conciliares expresaban así la necesidad de una pastoral unitaria y orgánica de las vocaciones sacerdotales y consagradas a nivel universal y local (CD 15; OC 24).

A partir del Concilio quedará claro en todos (pastores y fieles) que existe una sola Obra Pontificia para las vocaciones sacerdotales y consagradas al servicio de toda la Iglesia universal (cf. Secretaría de Estado de Su Santidad, 18 de marzo 1967, prot. n. 89806).

\subsubsection{La Pastoral de las vocaciones en el Concilio}

Teniendo como base la pastoral general de la Iglesia, el Concilio diseñó un proyecto específico de pastoral de las vocaciones. Afirmó en primer lugar que el «deber» de promover las vocaciones pertenece a toda la comunidad cristiana (OT 2; PO 11). Recordó que la representación visible de la variedad y de la unidad de las vocaciones se halla especialmente en la asamblea eucarística, momento culminante de la vida eclesial (SC 14). Por eso el Concilio pasó revista a los agentes de pastoral vocacional: el primer oficio del Obispo (LG 20; CD 15; OT 2; AG 38); tarea eminente del sacerdote (PO 11; OT 2; PC 24; AG 38), de los religiosos y las religiosas (PC 24; AG 40; OT 2), de los responsables de la vida misionera (AG 15-16, 18, 29, 36), tarea privilegiada de los padres (LG 11; OT 2; PO 11; PC 24; AG 41) y de otros educadores (OT 2; PO 11).

El Concilio, en fin, enumeró «los medios» tradicionales y nuevos de la pastoral vocacional, que adquieren mayor eficacia cuando están favorecidos por una imagen positiva de la Iglesia, hasta llegar a producir simpatía y consenso en la juventud de hoy (OT 2; PO 11). Pero esta variedad de personas y de medios debía encontrar un punto de encuentro para una cooperación armoniosa. $Y$ ahora el Concilio, por razones de lógica pastoral, toma en consideración un instrumento operativo idóneo: LA OBRA DE LAS VOCACIONES 6 .

6. El Dicasterio acoge respetuosamente la estructura de la POVE renovada por el Concilio y con el art. 4 y 11 del Reglamento interno se comprometía a custodiar su finalidad y las competencias, mientras los intereses de todos y la cooperación de cada uno a la causa de las vocaciones fueron la respuesta inmediata de las Diócesis, donde la desaparecida Obra de las Vocaciones se transformaba entonces en institución diocesana bien definida, para garantizar coordinación e impulso, en el sector específico, a la pastoral de los sacerdotes, de los consagrados y el apostolado de los fieles. La Obra de las vocaciones local asumía el nuevo nombre de "Centro Nacional (o Diocesano) para las Vocaciones al sacerdocio y a la vida consagrada", bien regulada por estatutos y ordenamientos adaptados y puestos al día, al servicio de una pastoral vocacional orgánica y de conjunto. 


\subsubsection{Jornada Mundial de Oración por las Vocaciones}

Pablo VI, en fidelidad a las directivas del Concilio y en un momento en el que los Padres había promulgado la Constitución sobre la liturgia y se disponían a aprobar la Constitución dogmática sobre la Iglesia, instituía la Jornada Mundial de Oración por las Vocaciones (23 de enero de 1964), preparada por el Movimiento Internacional «Unión de Oración por las Vocaciones» de san Aníbal María di Francia, como primer signo de aquella esperada coordinación mundial de la pastoral de las vocaciones al sacerdocio y a la vida consagrada. Desea por esto una celebración «única», o sea, para todas las vocaciones de especial consagración, mediante la «plena colaboración» y el «mutuo acuerdo» de las Congregaciones interesadas. En los cuarenta y cinco años siguientes, en los Mensajes anuales para la Jornada Mundial, los Sumos Pontífices siempre tendrán unidos los dos goznes de la jornada, la Iglesia y la Liturgia, y subrayarán siempre el tema de la oración y la acción por todas las vocaciones.

\section{RENOVACIÓN Y EVOLUCIÓN}

\subsection{Los tiempos modernos: crisis de las vocaciones y nueva evangelización}

El espíritu del Concilio invade la comunidad eclesial y le mueve hacia un compromiso evangelizador; el restablecimiento de los grupos, las asociaciones y los movimientos juveniles; la renovación de la catequesis; la valoración de la Iglesia local; la corresponsabilidad de los miembros activos de la parroquia en el apostolado; la reflexión más atenta sobre los ministerios y las diferentes vocaciones específicas dentro de la única y común vocación cristiana.

Después del Vaticano II la POVE asumía el encargo de la renovación: desarrollaba un programa de intervenciones de amplio espectro que podríamos dividir en cuatro fases o momentos estrechamente unidos entre sí en un proceso de continuidad y desarrollo, o sea: la fase internacional, la fase nacional, la fase diocesana y la fase de puesta a punto y relanzamiento, llamada continental.

2.1.1. Primera fase: «fase internacional». Esta fase, que abarca el quinquenio del inmediato post-Concilio (1965-1970), está caracterizada por diversos encuentros promovidos con la única finalidad de sensibilizar ante todo a los directores y responsables de las vocaciones de las diversas naciones.

En esta y otras iniciativas sucesivas se ha puesto en marcha un procedimiento ya ensayado: recoger experiencias y sugerencias de toda la Iglesia, para después ofrecer los resultados de las mismas en beneficio de toda la Iglesia universal.

Estos Congresos, convocados en un breve espacio de tiempo entre los años 1966, 1967, 1969, 1971, tuvieron el mérito de animar a la profundización teológica sobre vocación y vocaciones, llamar fundamentalmente a la inserción del interés por las vocaciones en la pastoral orgánica, subrayar la responsabilidad 
del clero y de las personas consagradas, aclarar la colaboración de los laicos, particularmente de la familia, e indicar las opciones operativas y los criterios pedagógicos requeridos por los tiempos.

El primer Congreso Internacional de Directores Nacionales, de 1966, tiene el mérito de llamar la atención sobre algunas recientes e importantes directrices del concilio: profundización teológica; colaboración a favor de todas las vocaciones; actividad por las vocaciones inserta en la pastoral de conjunto; atención a los jóvenes de distinta edad, sin desdeñar a los más maduros, también para colmar más rápidamente los vacíos que se abrían en los institutos formativos.

El segundo Congreso internacional, de 1967, profundizó en aquellos puntos del Concilio que trataban de la relación entre personas consagradas y vocaciones y esperaban una pedagogía más atenta a las características de las nuevas generaciones.

El tercer Congreso Internacional, de 1969, aportaba una buena contribución a la aplicación de las directrices del Concilio que se refería al cuidado de dedicarse también a los jóvenes de mayor edad y madurez, dotados de diversas disposiciones, sobre las cuales pueden obrar favorablemente las ayudas de la gracia y una ilustrada acción educativa.

El cuarto Congreso, de 1971, resumía problemas y experiencias del primer quinquenio postconciliar, durante el cual se había buscado actualizar las enseñanzas y las directrices del Concilio en orden a las vocaciones. Por otra parte, el Concilio ofrecía una aportación a los episcopados que estaban a punto de elaborar sus «Planes de Acción» nacionales para todas las vocaciones. El trabajo por aplicar el Concilio entraba de hecho en una nueva fase.

2.1.2. Segunda fase: fase «nacional». Se desarrolla en los años 70. Ha tenido como puntos de referencia la elaboración de Planes o Programas Nacionales para las vocaciones por parte de las Conferencias Episcopales; y la celebración del I Congreso Internacional por las vocaciones sacerdotales y consagradas, para estudiar dichos «Planes Nacionales»; la Congregación dirige a los Episcopados la invitación a elaborar y publicar para el propio país un «programa o Plan de Acción Nacional para las Vocaciones» ${ }^{7}$.

7. Las Conferencias episcopales respondieron inmediatamente. A la POVE llegaron cuarenta Planes Nacionales de los siguientes países: Argentina, Bolivia, Brasil, Colombia, Costa Rica, Cuba, Ecuador, El Salvador, Guatemala, Haití, Honduras, México, Panamá, Paraguay, Perú, Puerto Rico, República Dominicana, Uruguay, Venezuela, Canadá, Estados Unidos, Jordania, Israel, Chipre, Líbano, Siria, Irak, Malabar, Alemania, Austria, Bélgica, Escocia, España, Francia, Holanda, Inglaterra, Irlanda, Italia, Luxemburgo, Malta, Polonia, Portugal, Suiza, Filipinas. Los «Planes de acción» de los Episcopados constituyen una notable documentación de los esfuerzos hechos para dar fiel ejecución a las enseñanzas y las directrices del Concilio. En particular bajo el aspecto doctrinal, los documentos de los episcopados ilustran la vocación cristiana fundamental, sobre la cual, por una llamada especial, se posan las vocaciones consagradas, cada una con su dignidad y necesaria en el conjunto de la vida de la Iglesia. En el aspecto de las personas responsables, subrayan la primordial misión de los Obispos en cada Iglesia y de los Epis- 
Este primer Congreso Internacional de Obispos y Delegados de Conferencias Episcopales se celebró en Roma, del 20 al 24 noviembre de 1973. La Plenaria de 1970 había concebido el Congreso de los Obispos en unión con los «Planes de Acción Nacional». De hecho, toda la rica documentación de los Planes llegados a Roma, se convierte en objeto del estudio de este Primer Congreso Internacional de Obispos y otros responsables de las Vocaciones. El Documento conclusivo del Congreso de 1973, inspirándose en los grandes temas del Concilio, buscó aplicarlo a las circunstancias actuales:

-Reafirmó la necesidad de una reflexión teológica segura sobre la vocación y las vocaciones para presentarla de forma comprensible a los fieles y a los jóvenes de hoy.

-Resaltó las exigencias importantes de una pastoral específica eficaz.

-Expuso los principios de una pedagogía actual y profunda.

-Exhortó a perfeccionar la organización.

\section{Podemos sintetizar los resultados del Congreso en cuatro puntos:}

-Necesidad de una reflexión teológica segura. La pastoral de las vocaciones debe fundamentarse en una base doctrinal expresada en un lenguaje que incluya los problemas del hombre de hoy y debe respetar la visión de fe. «El Señor nos invita a pedir al Señor de la Mies que envíe obreros a su Mies». Es esencial acoger esta invitación: sin oración habitual, insistente, confiada, no existe verdadera pastoral vocacional. La vocación, además, debe ser comprendida en el marco de la Iglesia. Toda vocación de especial consagración está antes que nada al servicio de la Iglesia a su vez y al servicio de los hombres.

copados en su propia jurisdicción, ayudados por el clero, religiosos, familias, educadores y la comunidad creyente en general. En el aspecto de la actividad pastoral, presentan la pastoral de las vocaciones como momento privilegiado, con sus tiempos (p.e.: las Jornadas Mundiales) y métodos específicos, pero con la aspiración a insertarse ordenada y profundamente en la normal cura de almas. En el aspecto pedagógico reclaman la exigencia de una educación en la fe, en la vida cristiana, en el compromiso apostólico, como premisa a la ulterior profundización educativa en orden a la vocación consagrada. En la pedagogía de la vocación adquiere particular relieve el valor del ejemplo y del testimonio de las personas consagradas. Cada elección en tal sentido necesita, en circunstancias normales, estar sostenida por la presencia ejemplar de otra vida consagrada, que sabemos ser serena, confiada, operante. Cada resto de incertidumbre juvenil frente a la elección eclesial puede ser más fácilmente superada, cuando el ambiente eclesial ofrezca una imagen positiva de sí y de su misión entre los hombres de hoy. En el aspecto organizativo, confirman que en el seno de las Conferencias Episcopales operan opuestas Comisiones competentes en el sector de las vocaciones. De las mismas Conferencias dependen, casi por doquier, los Centros o Secretariados nacionales de vocaciones, con conexiones a nivel regional y diocesano; la unión de estas organizaciones, modeladas bajo los auspicios del Concilio, más o menos adoptadas en todas las naciones, responde al criterio de garantizar la necesaria unidad de dirección unida con la adaptación lógica en las circunstancias locales. En el aspecto operativo demuestran que no se puede confiar en iniciativas espontáneas y sin coordinación, sino que es necesario reunir las fuerzas disponibles para actualizar un verdadero programa, atentamente elaborado, de modo que lo mejor de la posibilidad apostólica se ponga humildemente al servicio del Espíritu que dispensa sus dones como quiere. 
-Pastoral específica de las vocaciones. Ésta no puede desarrollarse si no es dentro de una pastoral general, de la cual es una dimensión esencial. La pastoral específica general debe atender a todas las vocaciones de especial consagración, esto es vocaciones al ministerio presbiteral y diaconal, a la profesión de los consejos evangélicos en las Congregaciones Religiosas y en los Institutos Seculares; como también las vocaciones a los nuevos ministerios y a nuevas formas de vida consagrada, que el Espíritu pudiera suscitar. Se subraya, además, el esfuerzo general de evangelización, la importancia de la catequesis y la dirección espiritual, el papel de la familia y la comunidad parroquial, la pastoral de la juventud y de adultos. Respecto a los jóvenes, se insiste en presentarles el mensaje evangélico íntegro, centrado en la persona de Cristo, para ayudar a cada uno a asumir el propio papel en la Iglesia. Conviene también descubrir los valores positivos de los jóvenes de hoy, primeras respuestas a la llamada de Dios.

-Principios para una pedagogía de la pastoral de las vocaciones. Los elementos subrayados aquí son: responsabilidad de los Obispos en la pastoral de las vocaciones, necesidad de la formación en la plegaria para cualquier itinerario pastoral, papel insustituible del testimonio del sacerdote y de las personas consagradas. «No en los libros, sino en el contacto directo con las personas es donde se aprende qué es la vida del sacerdote o de una persona consagrada».

-Organizaciones de la pastoral vocacional. El Centro diocesano es el principal órgano de coordinación de la pastoral de las vocaciones con el Plan Diocesano y sobre todo con la pastoral juvenil. La «Jornada Mundial» ofrece a los pastores la oportunidad de resaltar la importancia y la belleza del servicio sacerdotal, de los otros servicios eclesiales, así como de la vida consagrada en la Iglesia.

2.1.3. Tercera fase: "fase diocesana». Se desarrolla en los años 80 , y ha constituido el paso decisivo para hacer operativas las directrices conciliares. Se caracteriza por:

-la preparación de los Planes diocesanos para todas las vocaciones por cada obispo;

-la celebración del II Congreso Internacional de Obispos y otros responsables de las Vocaciones Eclesiásticas, desarrollado en el Vaticano de 10 al 16 de mayo de 1981;

-la preparación y divulgación del Documento Conclusivo, como guía segura y autorizada de toda la pastoral vocacional.

En efecto, parecía que no era suficiente un Plan Nacional que no viniese arraigado en la situación concreta de cada diócesis. En última instancia es en la Iglesia local donde se puede desarrollar un servicio decisivo bajo la directa responsabilidad de los propios pastores. Los Planes Diocesanos enviados fueron más de 700 y llegaron de todas las partes del mundo. Este hecho se puede considerar como signo de una convicción cada vez más arraigada en la comunidad diocesana, a saber, no se puede llevar a cabo una pastoral de las voca- 
ciones inteligente y fecunda sin un proyecto orgánico que indique contenidos y medios, estructuras e iniciativas, elecciones pastorales y líneas de acción que comprometan de manera continuada a la comunidad.

Con el título Evolución del cuidado pastoral de las vocaciones en las Iglesias particulares; experiencias del pasado y programas para el futuro, se publicó el Documento Conclusivo del Congreso en la Políglota Vaticana en lengua inglesa, francesa, española, alemana, portuguesa e italiana. Sus líneas principales son:

-Fundamentar la pastoral de las vocaciones en una sólida base bíblica y teológica de la vocación a la luz del Vaticano II.

-Admitir el Concepto de «Pastoral de las Vocaciones» como una acción inserta en la pastoral de conjunto.

-Construir comunidades eclesiales vivas y todas ellas ministeriales (diócesis, parroquias, movimientos, familias, escuela, etc.).

-Comprometer a toda la comunidad y a todas las personas, concienciando sobre todo a las personas que tienen mayor responsabilidad (obispos, presbíteros, consagrados, misioneros).

-Promover todas las vocaciones, pero dar prioridad efectiva a la vocación presbiteral, diaconal, religiosa, consagrados en Institutos Seculares misioneros.

-Respetar las opciones fundamentales indicadas por la Iglesia en la pastoral vocacional (oración, catequesis, testimonio) considerando la plegaria «valor primario y esencial».

-Dar prioridad, en el tema vocacional, a los jóvenes, aunque el mensaje vocacional se dirige a todos.

- Hacer la propuesta vocacional con coraje y claridad.

-Aceptar un sano pluralismo en el acompañamiento vocacional, regional, diocesano respetando los «planes de acción» preparados por los Obispos.

2.1.4. Cuarta fase: "desarrollo y relanzamiento continental». Se halla en vías de realización. Está constituida por la celebración de Congresos Continentales o de áreas geográficas afines, por una promoción de las vocaciones que responda mejor a la necesidad de los diversos países.

El primer Congreso Continental ${ }^{8}$ se celebró en la Iglesia de América Latina, Itaici, San Pablo, 23-27 de mayo de 1994. Se concluye con un Documento Declarativo. Juan Pablo II aprobó y animó desde el principio la celebración de tales

8. «La Pastoral de las Vocaciones en el Continente de la Esperanza» ha sido el tema del Primer Congreso Continental Latino-Americano sobre las vocaciones celebrado en Itaici, São Paulo, del 23 al 27 de mayo de 1994, con la participación de 187 miembros entre cardenales, obispos, sacerdotes, diáconos, consagrados, consagradas y laicos. El Santo Padre (Carta de la Secretaría de Estado, prot. 330.670 de 30 de agosto de 1993 de orientación del Congreso) ha querido poner de relieve este acontecimiento anunciando la celebración del mismo en el mensaje para la XXXI Jornada Mundial de oración por las Vocaciones: «La celebración de la JMOV coincide este año con un importante acontecimiento eclesial: la inauguración del 'Primer Congreso 
Congresos Continentales. Para este primer Congreso para América Latina, no sólo ha aprobado la iniciativa (Carta de la Secretaría de Estado Prot. n. 330.670, 30 de agosto de 1993), sino que ha enviado un Mensaje personal a los organizadores y participantes. "Este Congreso en América Latina -son sus palabras- es el primero a nivel continental, y con él se inaugura una serie que, con la ayuda de Dios, tendrá lugar después en los diversos Continentes, en los que la Iglesia es sacramento de unidad y anunciadora del mensaje de Cristo entre las gentes».

Los objetivos perseguidos por el Congreso son cuatro:

- «Tomar conciencia de que la nueva evangelización exige en el continente Latino-Americano una mejor calidad y un mayor número de vocaciones a los ministerios ordenados y a la vida consagrada en sus varias formas que responden a la espera de nuestro tiempo».

- «Promover la integración de la pastoral juvenil con la pastoral vocacional, comprometiendo la pastoral familiar y la pastoral catequética en un mayor compromiso en la animación, el discernimiento y el acompañamiento de los jóvenes llamados a responder con generosidad a la llamada del Señor».

- «Crear en la comunidad cristiana itinerarios permanentes de formación espiritual juvenil y ofrecer a los jóvenes llamados un adecuado acompañamiento vocacionalı.

- «Instituir organismos de colaboración o de integración para una pastoral vocacional de conjunto y orgánica».

Sobre la organización del Congreso. El Congreso, promovido por la Santa Sede, fue gestionado por la Congregación para la Educación Católica, donde tiene su sede la «Pontificia Obra para las Vocaciones Sacerdotales y Consagradas», por la Congregación para los Institutos de Vida consagrada y las Sociedades de Vida Apostólica, por el CELAM y por el CLAR, y fue organizado por el Secretario General del Congreso Mons. Enrique Chemello, Obispo de Pelotas. El número de participantes ascendió a 187.

Sobre la celebración, podemos decir que tres fueron las temáticas de fondo afrontadas por el Congreso:

-análisis de la pastoral vocacional de hoy;

-valoración del trabajo de la pastoral vocacional en la pastoral orgánica de los diversos países;

-sugerencias para un nuevo impulso para dar a la pastoral de las vocaciones de especial consagración.

Continental Latino-Americano sobre el cuidado de la pastoral a favor de las vocaciones de especial consagración en el Continente de la esperanza'. Tal asamblea se propone desarrollar un profundo trabajo de verificación, de animación y de promoción vocacional. Mientras expreso vivo aprecio por esta iniciativa pastoral, dirigida al bien espiritual no sólo de América Latina, sino de la Iglesia entera, invito a todos a sostenerla con la plegaria unánime y confiada». 
Cada una de estas temáticas fue examinada desde diversas prospectivas y ángulos, con auxilio de cinco «ponencias» de estudio e información y dieciséis "comunicaciones» de experiencias operativas. Se toma conciencia, en el seno de la comisión, del significativo aumento en número y calidad de las vocaciones en todo el Continente: los seminarios y algunas instituciones similares, tanto diocesanos como religiosos, se encontraban numéricamente abundantes de nuevas vocaciones en muchos países. Si bien las vocaciones han experimentado un aumento real en todas las Iglesias particulares, era sabido que tal incremento no era aún proporcionado al incremento de población.

El Documento Conclusivo (Seminarium, De primo Congressu Continentis Latinoamericanae ad vocationes fovendas, anno XXXIV, n. 3, 1994). La celebración del Congreso llevó en breve tiempo a algunas conclusiones que desembocaron en el «Documento Declarativo del $1^{\circ}$ Congreso Continental Latino-Americano». Este breve documento ha adquirido una particular importancia para las 23 naciones de América Latina, empeñadas en dar una respuesta adecuada a la opción preferencial de la promoción de las vocaciones, indicada por la Conferencia Episcopal de Santo Domingo, sobre la promoción de las vocaciones. Las instancias del Documento se pueden sintetizar así:

- La PV es una acción mediadora, que nace del anuncio de la Palabra de Dios, sostenida y sustanciada por la plegaria, y trata de poner a todo creyente frente a la responsabilidad de su llamada. Cada agente vocacional debe ser consciente del carácter relativo, de mediación de su acción, sin asumir posturas que contradigan en la práctica la identidad y la función de quien debe sólo facilitar la comunicación entre dos polos, entre Dios y el hombre. La vocación primera de ser estrategia y misterio.

-Ésta es función de toda la Iglesia: «Toda la Iglesia permanece en estado de vocación y de misión, y además cada miembro de la Iglesia, cada uno por su parte se encuentra en estado de vocación y misión», y tiene por tanto precisa responsabilidad en relación al problema vocacional como «problema fundamental de la Iglesia», como dijo Juan Pablo II. Del todo injustificado el clima de silencio, dejación, indiferencia, irresponsabilidad todavía hoy detectable en lo que respecta a muchos de los agentes de pastoral vocacional y educadores.

-Es parte y elemento imprescindible de la pastoral eclesial global: «en el marco de un compromiso generalizado de toda la Iglesia particular está emergiendo la convicción de que la pastoral vocacional no es un simple ámbito o sector de la pastoral de la comunidad cristiana, sino la perspectiva unificadora de toda la pastoral vocacional». «Una pastoral de las vocaciones se podrá realizar sólo dentro de una pastoral global que lleve a una re-evangelización de toda la comunidad eclesial, por una parte, y de toda la comunidad humana en la que esta comunidad vive, por la otra». Si además la pastoral vocacional se insertase orgánicamente en la pastoral de conjunto, se superarán tanto la colateralidad pastoral co- 
mo el proceso de marginación de la fe, relegada junto y casi al margen de otros caminos pastorales: sea en el activismo que multiplica iniciativas de naturaleza varia, sin preocuparse de que converjan en un núcleo maestro y convincente, sea la delegación que reserva la tarea a cada uno dejándolo aislado.

-La PV es también parte y componente imprescindible de un programa de formación permanente. Gracias a esta interdependencia entre la Animación Vocacional (AV) y la Formación Permanente, cada consagrado y presbítero construye su unidad de vida, mientras la acción concorde de todos adquiere eficacia y fuerza; gracias a esta estrecha y natural correlación entre un instituto o una diócesis que se compromete seria e inteligentemente en la AV no resta medios ni energías a otros sectores vitales, ni privilegia un ámbito en prejuicio de otros, sino que promueve una implicación general: en realidad hace un discurso de cara a todos, discurso de formación de cada uno y de renovación de la comunidad.

-Por último, la PV abarca todas las expresiones de la vocación cristiana. Por esto, según el Documento conclusivo, «la vocación y las vocaciones se tienen que convertir en tema fundamental de la predicación, la plegaria, la catequesis. Y no basta con que el tema se trate de forma directa: debe estar presente, como anuncio indirecto, también en otros momentos de la predicación, la plegaria, la catequesis». Por supuesto, no debe cesar la indispensable actividad específica de cara a las vocaciones consagradas. Esto significa que la comunidad, por un lado, dirige su pastoral vocacional a todos los bautizados; por otro, promueve de forma articulada las demás formas de vocación consagrada. Esta no es, en efecto, una actividad unilateral, como no es actividad separada de la pastoral de conjunto, ni marginal, ya que se dedica al problema fundamental de la Iglesia.

\subsection{Segundo Congreso Continental para las vocaciones al sacerdocio y a la vi- da consagrada en Europa ${ }^{9}$}

La pastoral de las vocaciones en Europa se encontraba con que debía repensar globalmente su misma «justificación», además de su metodología, la cual una vez había sido nueva e incluso se había exportado; había tenido «retornos» cargados de muchas luces y sombras precisamente en la secuencia de la elaboración de una teología y una pastoral no abstractas, sino atentas a la inculturación, al contexto, al dinamismo de la historia... En aquel momento, tal teología y pastoral de las vocaciones ya no podía hacerse valer para el occidente de hoy porque era un escenario totalmente cambiado y requería la elaboración de una estrategia pastoral de evangelización a secas y de anuncio vocacional nuevos.

9. Tras el Congreso Continental Latino-Americano, 23 a 27 de mayo de 1994, Itaici (São Paulo, Brasil), la Sede Apostólica prepara el proyecto para celebrar el «Congreso Europeo sobre Vocaciones al sacerdocio y a la vida consagrada en Europa». Los Dicasterios que participaron más directamente en la preparación del Congreso de Europa fueron: a) La Congregación para la Educación Católica, en la que tiene su sede la Pontificia Obra para las Vocaciones; b) La 
2.5.1. La secretaría general había recogido de la base estos objetivos:

-Profundizar sobre todo en los aspectos teológico-pastorales en sintonía con la eclesiología del Vaticano II, considerando la pastoral de las vocaciones en constante relación entre el misterio de la Iglesia y la identidad sacramental carismática de los llamados.

-Intercambiar de modo más intenso los «dones» vocacionales entre las Iglesias hermanas de todo el Continente Europeo: conocimiento, profundización doctrinal, experiencias pastorales, iniciativas a nivel local y regional, colaboración en el campo formativo.

- Insertar más orgánicamente la pastoral vocacional en la pastoral ordinaria y extraordinaria, particularmente en la actividad juvenil, la familia y la catequesis: superando mentalidad de delegación, de pasividad y de pesimismo; responsabilizando a los párrocos y a los otros agentes pastorales; favoreciendo el aumento de la oración y de la espiritualidad vocacional; animando a la efectiva colaboración

Congregación para los Institutos de Vida Consagrada y Sociedades de Vida Apostólica; c) La Congregación para las Iglesias Orientales. El lugar de celebración del Congreso es Roma, Domus Mariae, del 5 al 10 de mayo de 1997, con participación de responsables de las diversas vocaciones consagradas y como tema: «Nuevas Vocaciones para una Nueva Europa».

Son numerosas y de diverso matiz las motivaciones para la decisión de que fuese Europa la sede del Segundo Congreso Continental.

De cara a la nueva evangelización. Europa contiene en sí tres importantes culturas de influencia mundial: Greco-Latina, Anglosajona, Eslava. La persistente «falta de unidad» que se nota al mirar al Continente es compensada por los esfuerzos para construir la Comunidad Europea y compartir valores humanos, morales y religiosos que han hecho de esta tierra punto de referencia para otros muchos países. Los últimos acontecimientos en Europa centro-oriental y las transformaciones socioculturales de Europa occidental requerían una intervención eclesial fuerte y unitaria para el futuro de las vocaciones en Europa.

La instancia central y prioritaria de la «nueva evangelización» en Europa, según la enseñanza constante del Santo Padre, nos hace caer en la cuenta no sólo de la necesidad de describir el estado de la situación cuantitativa y cualitativa de las vocaciones, sino aún más hace evidente la urgencia de profundizar sobre el significado y la contribución de la pastoral vocacional en las diversas Iglesias particulares: «El cuidado de la formación sacerdotal y de la pastoral vocacional -son palabras del santo padre- se inserta como momento privilegiado en el programa de la nueva evangelización» (8-7-1991). «Para esta sublime misión de hacer florecer una nueva era de evangelización en Europa requieren hoy evangelizadores especialmente preparados» (11 oct. 1985).

En los años del post-Concilio, Europa ha contribuido notablemente en la profundización de la teología y la pastoral vocacional a los ministerios sagrados y a las diversas formas de vida consagrada; ha vivido una rica experiencia en el campo organizativo y programático, consolidados en Centros Unitarios nacionales, regionales y diocesanos, puntos cardinales de toda la pastoral vocacional europea; experiencia de la que se enriquecen y siguen enriqueciéndose también comunidades cristianas de otros continentes.

Las Iglesias Europeas han desempeñado un papel fundamental en el anuncio misionero de Cristo a pueblos de los otros continentes. Tal obra resulta hoy particularmente necesaria y urgente en el espíritu de un recíproco intercambio de dones con las Iglesias hermanas. Porque se actualizan estos compromisos se subraya la fundamental importancia de individualizar la elección prioritaria de una pastoral vocacional que responda a las nuevas instancias emergentes al comienzo del tercer milenio.

La oportunidad del Congreso se ve más acentuada considerando las numerosas dificultades que todavía encuentra la pastoral vocacional en Europa. Son de grandísima actualidad los 
entre clero diocesano y religioso en el espíritu de Mutuae relationes, promoviendo la figura y el rol de la vocación monástica y su peculiar ascendencia en la vida de la Iglesia de Oriente y de Occidente; iluminando en la doble vía de acceso al sacerdocio de la Iglesia de Oriente: la vía celibataria y la vía matrimonial.

- Infundir confianza y esperanza a la comunidad y a sus pastores sobre la perspectiva vocacional, favoreciendo el espíritu de fe en Dios que llama siempre y por todas partes, proponiendo los aspectos positivos presentes en las distintas Iglesias particulares y pidiendo la creatividad y la responsabilidad de todos.

2.5.2. Los organismos responsables de la organización y preparación daban un aire internacional al Congreso: Pontificia Obra Vocaciones Sacerdotales y Consagradas (por la Congregación para la Educación Católica, para las Iglesias

acentos puestos por el Santo Padre hablando al VI Simposio del Consejo de las Conferencias Episcopales Europeas (11 oct. 1985): «Un análisis de la situación hoy en Europa, muestra, junto a reconfortantes signos de vocación y de reactivación, también una persistente crisis de vocaciones y el doloroso fenómeno de las defecciones. Las causas de este doloroso fenómeno son múltiples, y es preciso afrontarlo con vigor, sobre todo el que conduce a la aridez y a un alejamiento de desacuerdo corrosivo. De estos ambientes no nacen vocaciones».

La pastoral de las vocaciones en las naciones europeas está empeñada en superar la dificultad planteada por la nueva cultura, a ser activa en la renovación metodológica, a emprender una pastoral juvenil en dimensión vocacional con una presencia valiente y una confianza en los recursos pastorales de la Iglesia.

En algunos países europeos, sobre todo en occidente, se presenta el gran desafío de la elevada edad media de los sacerdotes, religiosos y religiosas, con la previsión estadística de un no fácil recambio en la actividad apostólica a todos los niveles.

Las vocaciones en los institutos religiosos son insuficientes para mantener las comunidades y sus obras, y algunas de ellas ven en peligro la propia supervivencia.

En las naciones del Este europeo, especialmente en aquellas que han añadido hace poco la experiencia de libertad, florecen las vocaciones, pero tienen difícil el discernimiento y la adecuada formación. En estas circunstancias el Congreso fue llamado a responder a algunos interrogantes: ¿Cuáles son las causas externas e internas que están en la base de la disminución de las vocaciones y de su perseverancia? ¿Qué nuevas vocaciones hacen falta para la nueva evangelización de Europa? ¿Qué soluciones presenta la pastoral vocacional frente a los diversos problemas y a los desafíos de carácter social y religioso? ¿Cómo promover la ayuda entre las Iglesias del Oeste, del Centro y del Este del Continente, "en un clima de genuina escucha y de recíproca acogida de las propias experiencias, dificultad y riqueza»?

Frente a estos y otros interrogantes, se reconoce que la decisión de afrontar la Europa de las vocaciones era un signo de la convicción de la importancia y la gravedad del problema que andaba perneando nuestras Iglesias particulares. La pastoral vocacional es por su naturaleza un servicio esencial para el futuro de la Iglesia. No se trata sólo de un ámbito, sino de la vida misma de la Iglesia y de su presencia en la historia. Se refiere a la estructura de la fe como experiencia y responsabilidad, como respuesta a la llamada de Dios. Por esto se va tomando conciencia de que la pastoral vocacional es una perspectiva unificante de toda la pastoral. Ella pide fe, trabajo y paciencia a los agentes de pastoral y a las comunidades cristianas como en ningún otro ámbito, porque pide sobre todo a los jóvenes no elecciones ad tempus como un año de voluntariado, de catequesis u otros, sino de por vida. Pero no es menor exigencia para los agentes de pastoral, los educadores y las familias, porque se trata de ponerse junto a las nuevas generaciones y ayudarles a madurar la propia libertad sobre elecciones duraderas, asentadas en valores socialmente en declive. De ahí de los objetivos más veces enunciados en la perspectiva de congreso: promover la esperanza, sobre todo en aquellos que en la comunidad cristiana son llamado en cada lugar a llevar el pondus diei et aestus (Mt 20, 12). 
Orientales y para los Institutos de Vida Consagrada y las Sociedades de Vida Apostólica); Consejo de las Conferencias Episcopales Europeas (C.C.E.E.); Unión de las Conferencias Europeas de Superiores Mayores (U.C.E.S.M.); Institutos Seculares Europeos (C.M.I.S.).

\subsubsection{Documentación del Congreso ${ }^{10}$}

2.5.3.1. Amplia consulta ${ }^{11}$. Para obtener una lectura real de la situación continental en toda la Iglesia europea se propuso una amplia consulta a diversos niveles: entre las conferencias nacionales de Obispos, de Superiores y de Superiores Mayores, de Presidentes de las conferencias nacionales de los institutos seculares, y entre la comunidad diocesana en sí misma considerada. Una comisión europea, sobre la base de las respuestas llegadas a la Secretaría General, preparó el Instrumentum laboris para el Congreso.

2.5.3.2. Estructura del Documento preparatorio ${ }^{12}$. Este Documento tiene como título La pastoral de las vocaciones en las Iglesias particulares de Europa y constituye ya una etapa del camino hacia la celebración del Congreso Europeo. Se intenta estimular y ayudar a una reflexión sobre esta curva de historia que

10. De Congressu abito ad Vocaciones ad Presbyteratum et ad Vitam Fovendas in Europa, en Seminarium, XXXVII (1997), n. 2-3.

11. Las respuestas al cuestionario, totales o parciales, llegaron de los siguientes países: Austria, Bélgica, Bielorrusia, Bosnia y Herzegovina, Bulgaria, Croacia, Finlandia, Francia, Alemania, Gran Bretaña, Grecia, Irlanda, Italia, Servia y Montenegro, Malta, Países Bajos (Holanda), Polonia, Portugal, República Checa, República Eslovaca, Rumania, Escocia, Eslovenia, España, Suiza, Suecia, Turquía, Hungría.

12. La pastoral de las vocaciones en las Iglesias particulares de Europa: con este título fue publicado el 18 de septiembre de 1996 el «Instrumentum laboris del Congreso Europeo» (IL), bajo la responsabilidad de la Congregación para la Educación Católica, para las Iglesias Orientales y para los Institutos de Vida Consagrada y las Sociedades de Vida Apostólica, bajo iniciativa de la Pontificia Obra para las Vocaciones Eclesiásticas. El texto comprendía una premisa, dos partes (respectivamente subdivididas en 7 y 4 capítulos) y un amplio apéndice que aporta 18 tablas estadísticas.

La premisa (nn. 1-6) precisa que el Documento preparatorio «quiere destacar del modo más objetivo posible la andadura cuantitativa y cualitativa de las vocaciones, la conciencia vocacional de nuestras Iglesias y las riquezas muy variadas de la pastoral vocacional desarrollada en los últimos decenios» A tal fin, el IL tiene en cuenta una amplia consulta realizada en Europa a varios niveles:

Primera parte: Una mirada al decenio 1985-1995

I. La tendencia numérica de las vocaciones. Considerando que las situaciones son muy distintas según los Países y regiones se nota que frente a un aumento del $4,27 \%$ de la población europea en el último decenio, el número de los sacerdotes diocesanos y religiosos registraba una disminución del $13 \%$, también porque el más reciente aumento de ordenaciones sacerdotales no compensaba la pérdida debida a defecciones y fallecimientos. Se registraba un aumento de seminaristas mayores (+23\%), mientras que los menores, de 1978 a 1994 , sufrían una caída del $52 \%$, particularmente a causa de la falta de natalidad, de la mayor definición de la fisonomía del seminario, de la mentalidad de los padres que preferían que sus hijos más jóvenes permanecieran en familia; fuerte caída también para los religiosos hermanos $(-30 \%)$ y hermanas $(-25 \%)$.

II. Las reacciones de la comunidad cristiana frente a la crisis. Van desde la tentación de pesimismo hasta reacciones positivas que se han manifestado en la recuperación de la oración 
precede al año dos mil desde el punto de vista vocacional; provocar una confrontación a nivel europeo en estos años, en los que en Europa se habla mucho con lenguajes diversos, que denuncian la lenta tarea de un hacerse unitario en torno a valores altos. Sobre todo se prefija el propósito explícito de favorecer el intercambio de «dones vocacionales» dando respuesta a las muchas demandas del Santo Padre en esta dirección: «La Iglesia universal conseguirá un gran pro-

por las vocaciones y la creciente conexión entre pastoral vocacional y pastoral juvenil. Bajo este aspecto, la situación presenta caracteres diversos en la Europa occidental y en la oriental.

III. El nivel cualitativo de las nuevas vocaciones. La tipología presenta la diversidad de la proveniencia la cual mayoritariamente está constituida por grupos juveniles, de la escuela de oración, del voluntariado. La edad media se ha desplazado sobre 18-20 años. Dos categorías juveniles: aquellos que privilegian la oración y los valores del espíritu, y aquellos que se muestran más sensibles a los problemas sociales.

IV. Elementos problemáticos en el mundo juvenil. Son complejos y contradictorios porque están influenciados por el subjetivismo, secularismo, materialismo. No falta, sin embargo, una clara emergencia de «nuevos valores» o sensibilidad positiva que tienen una explícita relación con la vida vocacional.

V. Situaciones de la pastoral juvenil y vocacional en la valoración de las Conferencias Episcopales. Sensibilidad nueva. Hay que registrar: el aumento de iniciativas de oración, mayor riqueza del magisterio de los Obispos (p.e. en Italia, en el último decenio, se han escrito 68 cartas pastorales sobre la materia), la renovación de las parroquias, la búsqueda de nuevos modelos, la creciente complementariedad de la pastoral juvenil y la pastoral vocacional.

VI. Algunas anotaciones de los Superiores y Superioras Mayores. Aparte de la conocida dificultad y preocupación, los Superiores y Superioras notan que por parte de los Obispos y párrocos los institutos religiosos «más que recibir apoyo, no reciben rechazo»; queda mucho camino para hacerlo en la animación vocacional; dos tercios de las familias religiosas no tienen plan pastoral propio, las distintas comunidades no siempre están preparadas ni comprometidas en la promoción de las vocaciones.

VII. Relieve sobre los Institutos Seculares por parte de las Conferencias Europeas. El número de las vocaciones es generalmente bajo. Pocos institutos presentan cierta estabilidad. Dificultad de un claro reconocimiento de la identidad de los miembros de los institutos seculares.

Segunda parte (nn. 54-90) Construir el futuro.

I. El marco teológico de la pastoral vocacional. Doble tendencia: por una parte, el esfuerzo por pasar de la experiencia a los caminos sistemáticos y progresivos de propuesta pastoral; por otra, el compromiso de radicar la praxis pastoral sobre una clara autoconciencia cristológica y eclesiológica en la busca de un serio equilibrio entre teología y praxis pedagógico-pastoral. Sin embargo, en muchas Iglesias particulares falta claridad en torno a la relación entre ministerio ordenado, vocaciones de especial consagración y todas las demás vocaciones.

II. La pastoral de las vocaciones en las Iglesias particulares. Estas son las líneas preeminentes: ser propositivos; afirmar el primado del Espíritu; privilegiar los tiempos vocacionales (semana, mes vocacional), insertándolos bien en el ciclo litúrgico; dar relevancia a la dirección espiritual; innovar el proyecto educativo de la escuela católica con precisas propuestas vocacionales; prestar atención a la dimensión femenina de la pastoral sobre todo la juvenil.

III. Proyectar la pastoral vocacional en la comunidad cristiana. Después de haber señalado los puntos débiles, el IL recuerda la importancia de la promoción de grupos y de las asociaciones como «lugares pedagógicos», el cuidado de los educadores, la valoración de la presencia de carismas, la colaboración entre CNV, CDV y organismos de participación, la aportación específica de los consagrados.

IV. La Europa de las vocaciones mira al futuro. Expuesto que la contribución del Congreso viene considerada sobre todo en perspectiva de cambio, se subraya la necesidad de tener el coraje de prefigurar una imagen distinta de la Iglesia, menos clerical y más participativa por parte de los laicos. Al final se enumeran las esperas e interrogantes de la comunidad eclesial de cara al Congreso y se formulan sugerencias y propuestas para su preparación y celebración. 
vecho si las comunidades locales se esfuerzan por desarrollar relaciones recíprocas, intercambiándose ayudas y bienes; surgirá así una comunión y cooperación de la Iglesia entre ellos, que hoy es más necesaria, para que pueda felizmente proseguir su trabajo de evangelización» (L'Osservatore Romano, 27 feb. 1993). Además se quiere conocer el parecer de las Iglesias particulares del continente acerca de promover las intenciones más valiosas, en vistas a dar un impulso, en los próximos años, a la pastoral de las vocaciones; ya para proseguir la línea de "opción preferencial de los jóvenes», ya para que en toda la Iglesia no falte una orgánica, inteligente y entusiasta pastoral vocacional, rica de todos aquellos elementos que permitan en ella la incisividad y el desarrollo. El Documento está dividido en dos partes, seguidas de un apéndice de estadística sobre la situación vocacional Europea. La parte primera, «Una mirada al decenio 19851995», describe: La tendencia numérica de las vocaciones (cap. I); Las reacciones de la comunidad cristiana ante la crisis de las vocaciones (cap. II); EI nivel cualitativo de las nuevas vocaciones (cap. III); Los elementos problemáticos en el mundo juvenil (cap. IV); La situación de la Pastoral juvenil y de la Pastoral vocacional según la valoración de las Conferencias Episcopales (Cap. V y $\mathrm{VI}$ ); La importancia de los Institutos seculares según las Conferencias Europeas (cap. VII). La segunda parte, «Construir el futuro», presenta: El cuadro teológico de la pastoral vocacional (cap. I); La pastoral de las vocaciones en las Iglesias particulares (cap. II); Proyectar la pastoral vocacional en la comunidad cristiana (cap. III); La Europa de las vocaciones mira al futuro (cap. IV).

\subsubsection{Las indicaciones del Congreso ${ }^{13}$.}

-El coraje de la profecía. Una pregunta ha querido hacerse el Congreso: ¿Qué falta en la pastoral vocacional de este tiempo que favorezca más eficazmente las respuestas? ¿Qué podría ser el «sustrato» idóneo para abrir campos nuevos en nuestra Iglesia? ¿En qué dirección va la profecía? De las respuestas aportadas por la comunidad eclesial es posible esbozar algunas orientaciones:

13. El desarrollo dinámico del Congreso ha seguido el íter de los contenidos divididos en cinco capítulos, distribuidos en cinco días.

-El primer día se ha leído la situación de las vocaciones en Europa. La mirada se ha dirigido al camino vocacional de nuestro continente, oportunamente relacionado con la situación mundial; y juntamente la atención se dirigió a las vocaciones en el contexto cultural entre complejidad y subjetivismo. Se ha prestado particular atención a los jóvenes, a los valores y desvalores en los que creen, a las dificultades y a la apertura que pueden obstaculizar o favorecer una propuesta vocacional. Se ha recortado sobre el fondo del primer día la figura bíblica del «Ver de Jesús». La mirada especular del Señor, que «viendo la muchedumbre siente compasión de ella, porque estaban cansados y abatidos, como ovejas sin pastor» (Mt 9,38$)$ y después el gran mandato: Rogate ergo Dominum messis - Rogad pues al Dueño de la Mies... (Mt 9, 38).

-El segundo día se ha dirigido la mirada a la situación vocacional con relación a la cultura, a la Iglesia comunidad de carismas y ministerios. El Congreso se ha preguntado: ¿en qué condiciones una Iglesia genera vocaciones? La respuesta ha sido precisa: la posibilidad de germinación está en una Iglesia en estado ministerial y misionera. Así en este día, yendo en la dirección de la concreción, se ha puesto el trabajo de cómo una Iglesia particular y cómo 
-En primer lugar en la dirección del primado del Espíritu; y de rebote gran importancia asume la plegaria por las vocaciones en formas diversas; de la lectio divina, los ejercicios espirituales, las jornadas de desierto o silencio cerca de comunidades contemplativas. Toma relieve el descubrimiento que muchos jóvenes hacen del silencio prolongado, incluso nocturno, ante la Santa Eucaristía. En esta larga experiencia ante Dios suele imponerse de modo explícito la autoconciencia vocacional o una reflexión seria sobre cómo orientar el propio futuro.

-Es necesario configurar una Iglesia de ministerios para la misión. El realismo exige que se tome nota del actual momento de evolución en el que es tangible la presencia simultánea de aspectos de caducidad y de pasado y de gérmenes prometedores de futuro. En verdad las estadísticas a nivel presbiteral y de congregaciones religiosas verifican un proceso de envejecimiento, no compensado por nuevos aportes vocacionales. El discernimiento pastoral pide a todos los Obispos y Superiores Mayores la valentía de prefigurar una imagen distinta de la Iglesia: menos clerical y más participativa por parte de los laicos. Esto sucede ya en muchas obras de promoción humana, en las escuelas, pero no menos también en la comunidad cristiana tradicionalmente confiada a los presbíteros.

una comunidad parroquial pueden traducir en concreto su dimensión vocacional; qué itinerarios de fe son posibles en la Iglesia particular. El icono bíblico que estaba en el fondo de la reflexión ha sido el de la comunidad de Corinto evocada por Pablo en su primera carta: «Hay diversidad de carismas pero un solo Espíritu» (1 Cor 12, 4).

-El tercer día se ha fijado en los jóvenes, en aquellos de nuestra generación frente a Cristo. Sí se ha enfocado la pastoral juvenil como pastoral vocacional. Por lo tanto en este día se han identificado los sujetos y los lugares pedagógicos de una pastoral juvenil en clave vocacional, con particular atención a la familia y a la escuela. De modo particular se hace esta pregunta: «¿Cómo ayudar a los jóvenes a superar la indecisión frente a las elecciones definitivas? ¿Qué caminos para una maduración vocacional definitiva?». El icono bíblico del joven en busca de Jesús: «Maestro dónde habitas» (Jn 1, 38) ha iluminado toda la temática.

-El cuarto día del itinerario congresual ha concentrado su atención en el problema nuclear de la pastoral vocacional: el «discernimiento», como actitud de cada pastor o educador a acoger la acción del Espíritu en el interior de la persona, para una propuesta pedagógica sabia que se convierta en camino de acompañamiento del joven en busca. El discernimiento pide una atención a sus aspectos espirituales y pastorales, a la persona del guía espiritual, a los caminos de formación en la Iglesia oriental y occidental. El icono que hacía referencia al tema del discernimiento vocacional ha sido aquel de Jesús en el evangelio de Juan «Fijando su mirada en él, dice: 'Tú eres Simón, el hijo de Juan, te llamarás Cefas'» (Jn 1, 42).

-El último día ha ocupado a la asamblea congresual en una especie de discernimiento comunitario. Todos los participantes en el Congreso, después de haber escuchado, pensando en su comunidad eclesial, han sido invitados a ofrecer los materiales y las proposiciones para elaborar una propuesta que ofrecer a las Iglesias de Europa.

Cada día el Congreso ha descansado sobre una reacción de fondo, que ha desarrollado el cuadro temático. El contenido de las relaciones ha sido profundizado en aspectos concretos a través del género literario de la comunicación; y vuelto a proponer en sus aspectos concretos mediante experiencias específicas en la ya citada mesa redonda o intervenciones en asamblea de viva voz. Bastante importante en la economía del Congreso el trabajo de grupo, porque es allí donde se ha dado de verdad la posibilidad de una participación activa y de ofrecer contenidos precisos y concretos de parte de todos. El Congreso, en conclusión, ha votado las proposiciones finales propuestas por los grupos lingüísticos, destinados a generar la plataforma del Documento Final. 
-Responder a la demanda de personalidades espirituales fuertes. Lo pide la pedagogía del modelo; lo pide la difusa debilidad del yo y de los mismos lugares pedagógicos (familia, parroquia, grupos). Una señal positiva y prometedora es la creciente demanda y propuesta de dirección espiritual. En algunas áreas geográficas prevalece la demanda con muy pocas respuestas; en otras es más generosa la propuesta y la disponibilidad por parte de los sacerdotes y de los religiosos y religiosas a postularse como guías espirituales de los jóvenes. De todas formas es prometedora para el futuro la común convicción, sobre todo a nivel de educadores, de la necesidad de una pastoral más personalizada y por lo tanto de la dirección espiritual.

-Apoyarse en los educadores. Se colige que el futuro de la Iglesia y de la sociedad, además la pastoral vocacional, tienen necesidad de manera particular de nuevos educadores en el contexto de la nueva evangelización. Estamos, en efecto, verificando la debilidad de muchos lugares pedagógicos (grupo, comunidad, oratorio, escuela y sobre todo la familia), de figuras espirituales. La vuelta de todos estos lugares a ser realmente educativos requiere la presencia de figuras espirituales de referencia segura: por lo demás guías espirituales motivados, robustos, límpidos. De aquí el interés por parte de las Iglesias particulares de formar a los formadores.

-No tener miedo del radicalismo evangélico como profecía. Hay, en efecto, una difundida solicitud a proponer a los jóvenes un Evangelio sine glossa, a través del testimonio renovado y no agotado de los consagrados. Se afirma en todos los tonos la urgencia de superar la patología del agotamiento en sacerdotes y consagrados, redescubriendo dentro de su misma llamada las razones de un rostro pascual. En particular se revisa en el «radicalismo evangélico» el mensaje más rompedor que pregonar con el anuncio y la vida en los vientos cruzados del secularismo, sobre todo como alternativa a la cultura enferma de sexismo exasperado, vivido en una sola dimensión. El radicalismo evangélico hay que presentarlo en toda su fuerza positiva como camino a la santidad, como única, verdadera posibilidad de auténtica realización humana en perspectiva evangélica.

-Promover el Congreso. El Santo Padre expresa el vivo deseo de que la celebración congresual sea precedida de un tiempo de preparación, hasta vivirlo en todas las Iglesias particulares de Europa, en la plegaria constante, confiada y específica al «Dueño de la mies para que mande operarios a su mies»; en la meditación y la reflexión sobre el deber que tiene hoy todo cristiano de promover las vocaciones sagradas; en la revisión y puesta a punto de la pastoral litúrgica, catequética, familiar y juvenil para una más creíble acción de anuncio, propuesta y acompañamiento de las vocaciones.

Los Centros Nacionales y Diocesanos para las vocaciones vienen señalados como los órganos de coordinación más importantes de esta fase preparatoria del Congreso. A ellos se dirige el encargo de sensibilizar a todos los miembros de la Iglesia a utilizar los propios dones de la mente y del corazón para una más res- 
ponsable promoción de las vocaciones sacerdotales y consagradas. Las comunidades eclesiales son invitadas a profundizar las instancias del Congreso y responder con la subsiguiente responsabilidad a las siguientes preguntas: 1. ¿Cuál es la identidad de los jóvenes europeos?; 2. ¿En qué valores creen?; 3. ¿Cómo traduce la Iglesia particular la dimensión vocacional en el plano pastoral?; 4. ¿Cómo concreta la parroquia la propia conciencia vocacional?; 5 . ¿Cómo puede la pastoral juvenil abrirse a la dimensión vocacional?; 6 . ¿Cómo ayudar a los jóvenes a superar la indecisión ante compromisos definitivos?

2.5.3.4. Compromisos para las Iglesias de Europa. El documento final, Nuevas vocaciones para una nueva Europa, se elabora por una especie de comisión congresual y es publicado dos meses después de su clausura, el 6 de enero de 1998, bajo los auspicios de tres Dicasterios de la Sede Apostólica: Educación Católi$\mathrm{ca}$, Iglesias Orientales, Institutos de vida Consagrada. Traducido a la vez en cinco lenguas, es enviado a todas las Iglesias particulares de derecho común, oriental y misionero. Actualmente el texto ha sido copiado y difundido en 62 lenguas.

a) Naturaleza del Documento. Se trata de un Documento Pastoral, fruto de una larga experiencia de las Iglesias de Europa, que han señalado el camino y la evolución de la pastoral vocacional postconciliar en el primer Continente. Es un gran documento por la puntualidad en el revelar la situación en su contexto; por su completa teología de la vocación; por la sensibilidad tanto en el aspecto antropológico como en el eclesiológico con el tema de la reciprocidad de todas las vocaciones bajo el signo de la comunión; por la atención pastoral dirigida no sólo y no tanto a elaborar estrategias de intervención, cuanto a presentar la vocación como dimensión connatural y esencial del anuncio cristiano y de la evangelización a las puertas del nuevo milenio; y en fin, por la constante preocupación pedagógica en la educación, formación y acompañamiento vocacional de los jóvenes de hoy.

La finalidad del documento es la de compartir con todas las Iglesias europeas el acontecimiento de gracia que el Congreso ha supuesto. La Comisión congresual para la redacción del texto, sin pretender hacer de éste una síntesis cuidada, ni presumir de exponer un tratado sistemático sobre la vocación, ha querido poner fraternalmente a disposición de toda la Iglesia que está en Europa y más allá de Europa, en sus varias denominaciones cristianas, los frutos más significativos del mismo Congreso: con un estilo que expresa lo más posible la voluntad de hacerse entender por todos, porque todos de una u otra manera son llamados a realizar su vocación y a promover la del que está cerca de él; con atención sobre todo de conjugar entre su reflexión teológica y la praxis pastoral, propuestas teóricas e indicaciones pedagógicas, para ofrecer una ayuda concreta y práctica a cuantos trabajan en la animación vocacional; sin pretensión alguna de decirlo todo, no sólo para no repetir todo aquello que está ya dicho en muchos documentos, sino para permanecer abiertos al misterio, a ese mis- 
terio que envuelve la vida y la llamada de cada ser humano, a ese misterio que es también el camino del discernimiento vocacional y que sólo acabará en el momento de la muerte.

b) Las partes del Documento conclusivo. El texto sigue la lógica que ha conducido los trabajos del Congreso: desde la existencia concreta a la reflexión sobre ello para volver ahora al existencial concreto. Es con la realidad de cada día con la que debe confrontarse la pastoral vocacional, precisamente porque es una pastoral en función y al servicio de la vida. En consecuencia se comienza con una tentativa sondeo sobre la situación, para después analizar el tema de la vocación desde el punto de vista teológico, y dar además un fundamento, una indispensable estructura de referencia a todo la secuencia del discurso. En este punto se inicia la parte más aplicable. De tipo pastoral, ante todo, o de grandes estrategias de intervención, y después de tipo más pedagógico, para identificar al menos algunas pistas orientadoras en el plano del método y de la praxis cotidiana. Quizás este aspecto mismo es el más esperado por los agentes de pastoral.

Por tal motivo el documento se extiende un poco en las secciones pastoral y pedagógica, pero sólo con el intento de ofrecer un instrumento útil para varios agentes. Hubiera sido deseo de la Comisión preparar un texto breve y esencial, pero ha parecido que el actual estado de la reflexión sobre la pastoral de las vocaciones requería una cierta articulación de análisis.

El Documento invita a dar un salto de calidad, a pasar de una concepción estática, que veía la vocación como un don predeterminado, como un plan rígidamente establecido, a un sentido dinámico de la vocación. La persona humana, más que «tener una vocación», está en «jestado de vocación!». Toda la vida del hombre es una llamada de parte de Dios y una respuesta de la persona a ser, vivir y obrar en la libertad según su diseño inescrutable.

Este concepto está bien expresado en todo el Documento: «cada vida es vocación cada hombre y cada mujer son un don de Dios al mundo, cada cristiano es un misionero de Dios en el mundo», recordando el famoso texto de la Populorum progressio de Pablo VI: «En el designio de Dios, cada hombre está llamado a una evolución, porque toda vida es vocación. Desde el nacimiento es dado en germen un conjunto de cualidades para hacerlas fructificar: su pleno desarrollo, fruto a un tiempo de la educación recibida, del ambiente y del esfuerzo personal, permitirá a cada uno orientarse hacia el destino propuesto por el Creador, dotado de inteligencia y de libertad, el hombre es responsable de su crecimiento, así como de su salvación. Ayudado y a veces impedido, por aquellos que lo educan y lo rodean, cada uno permanece, cualesquiera que sean las influencias que se ejercen sobre él, el artífice de su éxito o de su fracaso» (n. 15). La vocación, pues, inviste al ser humano permanentemente y se concreta en la respuesta personal, madurada en un admirable intercambio de gracia divina y libertad humana. Es fácil deducir los aspectos educativos y formativos en el descubrimiento y en la maduración de la vocación: como exigencias de una fidelidad creadora. 
Una vez descubierta y evidenciada la dimensión vocacional de la Iglesia y su función mediadora de todas las vocaciones, se deducen algunas consideraciones concretas, comúnmente aceptadas en el plano teórico, pero aún no asimiladas en la práctica.

- La pastoral de las vocaciones actúa como «efectiva participación» de todo el pueblo de Dios en la obra de las vocaciones (OT 2), no es un momento aislado o sectorial de la vida de la Iglesia, sino más bien su momento esencial y calificador. Por lo tanto «es necesario convencerse que un tal problema está unido de modo muy estrecho a toda la pastoral ordinaria» (Juan Pablo II a la Asamblea General de la CEI, 15 de mayo de 1979, n. 4).

-La responsabilidad en la promoción vocacional corresponde a toda la comunidad eclesial. En su interior después las diócesis, las Órdenes y Congregaciones Religiosas, las parroquias, las familias, cualquier otro miembro, todos los bautizados, cada uno según su papel, son corresponsables en esta acción diversificada y convergente.

- La pastoral de las vocaciones debe estar dirigida de modo global a todos los bautizados, de toda edad, dirigida a todas las vocaciones. No obstante, evitando cualquier forma de camuflaje y generalidad, la Iglesia promoverá una pastoral vocacional específica dirigida a las vocaciones sacerdotales y de especial consagración.

- La pastoral de las vocaciones pide un esfuerzo coral. Entre los servicios con los que la comunidad cristiana ejerce el papel de mediación para las vocaciones, alcanzan particular relieve: la oración, el testimonio, el anuncio, la orientación. Estos servicios son fruto de un esfuerzo coral que fundamenta una moderna pastoral de las vocaciones. La llamada nos viene más allá en los documentos de los Congresos específicos sobre la pastoral de las vocaciones y de otros autorizados documentos, como en el conocido Criterios directivos sobre las relaciones entre los obispos y los religiosos en la Iglesia, o simplemente Mutuae Relationes, que dice en el número 39: "Campo privilegiado de colaboración entre los obispos y los religiosos debe considerarse el compromiso pastoral por acompañan las vocaciones. Tal esfuerzo pastoral consiste en una acción concorde de la comunidad cristiana para todas las vocaciones, de modo que la Iglesia sea edificada según los planes de Cristo y según la variedad de carismas de Su Espíritu» ${ }^{14}$.

14. En el hecho vocacional esto por encima de cualquier otra cosa debe ser bien considerado: que es el Espíritu Santo, el cual «sopla donde quiere» (Jn 3, 8), quien llama a los fieles a diversos oficios y estados para el mayor bien de la Iglesia. Está claro que no debe ponerse obstáculo alguno a esta acción divina, sino, al contrario, se debe facilitar que cada uno responda con la máxima libertad a la propia vocación. La historia misma, por lo demás, puede testimoniar abundantemente que la diversidad de vocaciones, y sobre todo la coexistencia y colaboración de uno y otro clero, diocesano y religioso, no van en detrimento de la diócesis, más bien enriquecerán con nuevos tesoros espirituales y acrecentarán notablemente la vitalidad apostólica. Por lo tanto será oportuno que las múltiples iniciativas sean sabiamente coordinadas bajo la guía de los obispos: es decir, según las competencias que corresponden a 
Y más recientemente los Sínodos y los documentos post-sinodales, como Vita Consecrata, n. 64 (que pide un compromiso coral de toda la Iglesia, la activa colaboración de los pastores, religiosos, familias y educadores, tal como conviene a un servicio que es parte integrante de la pastoral de conjunto de cada Iglesia particular); Pastores Gregis, n. 54; Ecclesia in Europa, n. 39-40; Pastores dabo vobis, n. 38-39; Sacramentum Caritatis, n. $25^{15}$.

También en Novo Millennio Ineunte Juan Pablo II pide un «esfuerzo generoso por la promoción de las vocaciones al sacerdocio y de especial consagración. Es éste un problema de gran importancia para la vida de la Iglesia en todo el mundo» (n. 46; animamos a leer todo este número).

2.5.3.5. El desafío cultural del post-Congreso. Cuanto hemos examinado y elaborado por el Congreso pide un contraste entre «cultura» y «vocación», dos términos aparentemente no compatibles. El problema no está sólo en el crear en el sentir común de las personas una mentalidad favorable a la idea de vocación, y a las vocaciones; sino sobre todo, el de hacer llegar el discurso vocacional en su complejo a categoría cultural, sustrayéndolo de un tecnicismo pastoral que lo quería confinado a mera estrategia de supervivencia por parte de la institución eclesial.

Hoy se pone entre los desafíos culturales: la centralidad del problema educativo. ¿Qué desafío proviene hoy de la cultura y del contexto social en el que, por vocación, somos llamados a vivir? La respuesta, universalmente compartida, indicada muchas veces por el Papa, es la nueva evangelización. ¿Qué pide a la pastoral juvenil, a la pastoral vocacional? (se entiende como único sujeto destinatario). Creo que se puede afirmar que el desafío converge en la conciencia más atenta y más vigilante de la sociedad y de la Iglesia, para reclamar que se ponga

los padres y educadores, a los religiosos y a las religiosas, a los presbíteros y a todos los demás, que trabajan en el campo pastoral. Por eso este compromiso deberá ser asumido en común y al unísono, y con plena dedicación de cada uno; y el obispo mismo guíe el esfuerzo de todos hacia la convergencia de las acciones, y recuerde siempre que tales esfuerzos son en su raíz originados por el impulso del Espíritu. En consideración de esto, por tanto, urge también la necesidad de promover con frecuencia iniciativas de oración (Mutuae Relationes, n. 39).

15. A propósito del vínculo entre el sacramento del Orden y la Eucaristía, el Sínodo reflexionó sobre la preocupación que ocasiona en muchas diócesis la escasez de sacerdotes. Esto no sólo ocurre en algunas zonas de primera evangelización, sino también en muchos países de larga tradición cristiana. Ciertamente, una distribución del clero más equitativa favorecería la solución del problema. Es preciso, además, hacer un trabajo de sensibilización capilar. Los Obispos han de implicar a los Institutos de vida consagrada y a las nuevas realidades eclesiales en las necesidades pastorales, respetando su carisma propio, y pedir a todos los miembros del clero una mayor disponibilidad para servir a la Iglesia allí dónde sea necesario, aunque comporte sacrificio. En el Sínodo se ha discutido también sobre las iniciativas pastorales que se han de emprender para favorecer, sobre todo en los jóvenes, la apertura interior a la vocación sacerdotal. Esta situación no se puede solucionar con simples medidas pragmáticas. Se ha de evitar que los Obispos, movidos por comprensibles preocupaciones por la falta de clero, omitan un adecuado discernimiento vocacional y admitan a la formación específica, y a la ordenación, candidatos sin los requisitos necesarios para el servicio sacerdotal. 
en el centro el problema educativo, como explicación o precisión de un movimiento más general de nueva evangelización de la cultura contemporánea.

La centralidad del problema educativo es realmente exigida por la mayoría, pero sobre todo por las situaciones objetivas que todos conocemos bien:

-por la condición de orfandad en el cual se encuentran las nuevas generaciones, a causa de la dramática contumacia de la familia, provocada por serios complejos de inferioridad y de impotencia frente al problema de educar;

-la centralidad del problema educativo es reclamado por la misma condición de orfandad que niños y jóvenes viven en la escuela, allá donde se teoriza, o se vive de alguna manera, un «minimalismo educativo», también por un propagado «cristianismo latente» en régimen de libertad sumergida;

- la centralidad del problema educativo es situada por la urgencia de recuperar algunos valores latentes en la subjetividad juvenil: sobre todo el de la conciencia, de la persona;

-la centralidad del problema educativo es fuertemente exigida por la crisis de los mismos modelos «institucionales», hacia los que se orientaba como espontáneamente, por simpatía, la vida de los jóvenes.

La conciencia del problema educativo, hasta rescatar y reafirmar en simbiosis con una cultura vocacional, no puede sino apoyarse en el modelo "persona», para reacreditar, si acaso después, la significatividad de la categoría.

¿Qué preguntas se hacen hoy a todos los responsables de las vocaciones y en particular a los animadores, qué exigencias se pueden expresar? Ante todo se pide una seria conciencia eclesial.

La educación a la pertenencia eclesial, por otra parte no fácil, no se hace hablando de la Iglesia, sino haciendo experimentar una presencia activa, allí donde se hace visible la diversidad de dones y de vocaciones. El animador vocacional que se propone ocasionalmente en la comunidad cristiana, no puede limitarse a encender intereses pasajeros; sino que debe hacerse «animador de animadores» para asegurar una atención vocacional en el camino ordinario, ferial, de la misma comunidad.

Se postula una "clara conciencia educativa»; es por tanto la conciencia de los fines que deben orientar una sabia animación, el conocimiento claro y actual de los jóvenes y las jóvenes frente a la propuesta de fe, y una justa capacidad metodológica en el hacer pasar los valores.

Hoy tenemos necesidad extrema de "educadores» y de "educadores de animadores». El animador no puede contentarse con «reunir» en torno a sí. Para eso basta una guitarra, un campamento, un campo-escuela. El educador sabe apasionar por «alguien» o «por algo» que está más allá; y hace crecer; es capaz de suscitar amor por la vida.

Se pide, en fin, una «explícita conciencia vocacional». La conciencia educativa no puede no ser «conciencia vocacional». 
¿Qué es ese «más» hacia el que conduce el camino de la fe? No son solamente los valores. Los valores no fascinan tanto, sobre todo si están desdibujados. Ese «más» es la adhesión a una persona -Jesucristo-; es un proyecto interesante, que da sentido a la vida.

Por lo tanto en la mente del educador en la fe, la conciencia vocacional debe estar explícita, sobre todo para ayudar a la persona a realizarse en la verdad. Por eso, podemos decir que todo verdadero educador (animador, catequista, sacerdote o laico) es naturalmente animador vocacional.

Ahora todo esto no se improvisa, porque en el educador se ha verificado ya o debe verificarse aquel famoso paso de los criterios de realización de la vida: el educador es de verdad, el experto en el mundo desconocido, del mundo nuevo, del «ser» de la persona, de sus dinamismos espirituales. De aquí un esfuerzo implícito, animoso, de invertir en persona; el empeño de cada comunidad cristiana por la formación de los formadores. De otro modo el proyecto pastoral se encalla en el mismo escritorio sobre el que ha sido pensado. No se arriesgue a pensar proyectos o planes pastorales sin prestar una atención privilegiada, me atrevería a decir, pormenorizada, a la mediación educativa, a los educadores.

\section{Perspectivas}

La pastoral de las vocaciones tiene necesidad, sobre todo hoy, de ser asumida con un nuevo, vigoroso y más decidido esfuerzo de parte de todos los pastores y fieles, en la convicción de que éste no es un elemento secundario y accesorio, ni un momento aislado o sectorial, como una parte, aunque relevante, de la pastoral global de la Iglesia; es más bien una actividad inserta en la pastoral general de cada Iglesia, una preocupación que se debe integrar e identificar plenamente con la "cura de las almas», una dimensión connatural y esencial de la pastoral de la Iglesia, o sea de su vida y de su misión. Se impone ahora un discurso nuevo sobre la vocación, sobre la cultura y sobre la pastoral vocacional.

\subsection{Re-evangelizar}

Los Congresos queridos por el Santo Padre son una rica contribución a la nueva evangelización del mundo. Ésta se reclama en su triple significado:

- «nueva» en cuanto a lo cronológico... porque viene después de aquella y fundamental primera obra de evangelización de la cual nace y se ha forjado, a lo largo de los siglos, nuestra experiencia de Iglesia y, en particular, la cultura cristiana de los Continentes católicos;

- «nueva» en lo socio-cultural: porque debe vérselas, en nuestra sociedad occidental, con el fenómeno persuasivo del secularismo, con este tipo de familia y con esta generación de jóvenes, sin continuar soñando en tiempos pasados que ya no verán más; 
-«nueva» en lo pastoral: porque la pastoral: catequética, juvenil y familiar debe hacerse nueva en su ardor, en sus métodos y en su expresión (Juan Pablo II, Discurso a la Asamblea de Obispos del CELAM, 9 marzo 1983).

El mundo, aun estando secularizado, conoce situaciones y ámbitos en los cuales la fe continúa siendo vivida o en las que al menos emerge la necesidad de un remanente religioso o de una referencia a lo sagrado. No faltan, en efecto, ejemplos genuinos y positivos de adultos, familias y jóvenes que viven y encarnan el Evangelio en su existencia cotidiana y lo testimonian en los pliegues de la historia y en los diversos ámbitos de su tarea de trabajo, profesional, social, eclesial. Aun así, existen formas difusas de religiosidad, cargadas de valencia positiva, que aparecen interpretadas y a menudo purificadas. Basta pensar, por ejemplo, en las numerosas tradiciones de piedad popular, a los muchos que buscan manifestaciones extraordinarias y marchan a lugares en los que se espera obtener una curación o en que se anuncian apariciones, al difundirse del interés por ciertas formas de plegaria y de meditación conectadas con las religiones orientales, al rápido proliferar de nuevos movimientos religiosos o pseudo-religiosos, de grupos, de sectas. Para no hablar de todos aquellos que, en los momentos cruciales de su existencia, vuelven su rostro a la Iglesia y, a pesar de todo, de ella se espera cercanía, acompañamiento, gestos rituales, una palabra que ayude a encontrar el sentido global de la vida.

En la situación actual aparentemente caracterizada sólo por hechos exteriores de orden político, económico-social, asistimos también a la busca de nuevos valores y descubrimos la presencia de un profundo anhelo en la libertad política, en la construcción de una sociedad pluralista, a una prosperidad y libertad también económica. Sobre todo, como pone de relieve la Centessimus annus, los pueblos son llamados a preguntarse profundamente sobre la dirección que imprimir a los cambios acaecidos en el Continente, sus principios y sus pilares sobre los cuales fundamentar la futura convivencia.

\subsection{El brazo del Señor no se ha encogido}

Hoy, el problema del número suficiente de sacerdotes y de consagrados se hace sentir de manera preocupante e implica de cerca a todos los fieles: no sólo porque de ello depende el futuro religioso de la comunidad cristiana, sino también porque este problema es el preciso e inexorable indicador de la vitalidad de fe y de amor de cada comunidad parroquial y diocesana y el testimonio de la salud moral de las familias cristianas.

La situación vocacional se presenta actualmente de modo variado, a la manera de la problemática distinta de los cinco continentes:

-en trabajosa recuperación en países de Norte América, Europa y Australia;

-en constante incremento en países de África y Asia;

-en aumento en países de América Latina. 
La crisis de las vocaciones se manifiesta:

-en los países de elevado nivel de vida, como crisis de escasez de aspirantes;

-en los países con alto prestigio pastoral (particularmente en América latina) como crisis de formadores y, por tanto, de animación, orientación, formación;

-en los países pobres y con gran incremento demográfico (África, Asia) como crisis de estructuras educativas, de personal especializado y de inculturación.

Si en occidente el declive de las vocaciones obliga a la reestructuración del presente, en el tercer mundo el aumento de candidatos exige formación adecuada e inculturación verdadera en los diversos contextos.

En este contexto articulado y complejo, se puede y se debe pedir cuál es el perfil adecuado del anuncio del evangelio de la vocación.

a) Una fe madura y consciente. Si la «nueva evangelización» exige pasar de una fe de costumbre a una fe personal, luminosa, convencida y testimonial, la primera característica fundamental de «las nuevas vocaciones» mira a la fe. Es necesaria, en efecto, una fe madura y consciente a nivel personal y que sepa dar razón de sí misma incluso en las difíciles y variadas fronteras de nuestra civilización. Es necesario, en otras palabras, un «Saber sobre Jesús», que devenga cada vez más en "compresión» objetiva de él, hasta llegar a una genuina «comprensión teológica». De este modo, en particular los presbíteros evangelizadores, será posible hacerse cargo de la fe de los hermanos. A tal fin, una condición se presenta como irrenunciable: una adecuada formación teológica, que no consiste en la pura posesión de una serie de contenidos, sino en condición de hacer brotar y cultivar el «gusto del pensar teológico». Sólo así será posible afrontar la nueva situación a la luz de la Palabra y en una auténtica visión de fe. También Juan Pablo II ha hablado de una «preparación intelectual seria, desde el punto de vista de las ciencias humanas y sagradas» como de «una exigencia fundamental» para tener nuevos evangelizadores para la nueva evangelización.

b) Espiritu de «encarnación». Son necesarios, en segundo lugar, presbíteros, religiosos, religiosas que sepan vivir en continuo contacto con la gente, partícipes de sus problemas, de sus expectativas, dificultades y esperanzas. En otras palabras, las «nuevas vocaciones» son llamadas a nutrir y a vivir la dimensión típicamente «popular» de su ministerio. Este profundo espíritu de «encarnación», por un lado, no puede dejar de estimular cada vez más el «gusto por el pensar teológico» y, al mismo tiempo, lo ayuda a no caer en la abstracción estéril y distante, que estaría ya contra el Evangelio ya contra la teología.

c) Capacidad de una "relación cultural». En la misma línea, a las «nuevas vocaciones» de hoy y de mañana se le pide conocer seriamente la cultura contemporánea y saber confrontarse hasta el fondo con los dinamismos de la modernidad y de la postmodernidad. Lo que está en juego es, en efecto, la paciente capacidad de plegarse con amor y humildad sobre nuestra sociedad -con todas sus miserias, agobios y pesantez- para ayudarla a vivir en renovada y mayor 
plenitud el mensaje profundamente liberador del Evangelio en lo concreto de nuestra historia y de nuestra ciudad. Como se está reclamando un esfuerzo inteligente y continuo por una nueva inculturación del Evangelio, la cual-como recuerda la Redemptoris missio- no consiste en «una pura adaptación exterior, porque la inculturación significa 'íntima transformación de los auténticos valores culturales mediante la integración en el cristianismo y la radicalidad cristiana en las diferentes culturas'» (n. 52). «Es, pues, necesario compartir los sucesos de esta historia y sentirse hasta el fondo ciudadanos de este mundo, incluso viviendo y testimoniando la 'paradoja' de una pertenencia que se deja siempre juzgar e inspirar por la fe, recordemos las palabras que Pablo VI dice sobre el mundo en su testamento: 'No se piense que se le ayuda asumiendo sus pensamientos, costumbres, gustos, sino estudiándolo, amándolo, sirviéndolo'».

d) Familiaridad con la Palabra de Dios. Tanto la referencia a la Palabra de Dios como una profunda y cotidiana familiaridad con ella -según las preciosas indicaciones del mensaje que el Santo padre ha enviado a la Iglesia para la XXXIV JMOV- es condición imprescindible y prioritaria para una nueva y renovada pastoral de las vocaciones. De ahí se sigue que «nuevas vocaciones» tienen que crecer en el conocimiento y amor a la Sagrada Escritura, a través de un estudio humilde y orante y alimentando cada día con la lectio divina. Y será la misma Palabra de Dios vivamente guardada, suavemente saboreada, profundamente meditada y existencialmente asimilada lo más importante que tendrá para honrar y anunciar. Ella sola, en efecto, puede despertar también al hombre contemporáneo de sus ilusiones y sustraerlo de una existencia sin significado: de esta Palabra, por ello, las «nuevas vocaciones» se presentarán como mensaje humilde e incisivo.

e) Los valores del testimonio. Al mismo tiempo es necesario que, más allá de anunciar el Evangelio, ellas sean un evangelio, en obras y palabras. En efecto, es en el contexto de una Iglesia viviente donde cada cristiano de hoy podrá ver y experimentar realmente cómo, incluso en el contexto de las conquistas de la técnica..., gracias a la luz y a la fuerza que nos llegan del Evangelio, se puede comunicar mayor humanidad a la vida de las personas. Los presbíteros, las religiosas y religiosos, los primeros, deben sentirse interpelados por esta consideración. También para esto vale lo que escribía Pablo VI en Evangelii nuntiandi: «El hombre contemporáneo escucha con más gusto a los testigos que a los maestros, y si escucha a los maestros lo hace porque son testigos» (n. 41); «el mundo [...] reclama evangelizadores que le hablen de un Dios, que ellos conozcan y que les sea familiar, como si viesen al Invisible» (n. 76). Será sobre todo a través del testimonio de la caridad que se podrá presentar como evangelio y como testimonio auténtico: una caridad para con todos, especialmente para con los más pequeños y pobres, una caridad que se haga cercana a cada hombre y amor preferencial para los que tienen más necesidad de él. 


\section{LAS ESPERANZAS}

4.1. Urge un nuevo planteamiento de la pastoral juvenil y vocacional que implique una revisión del modo de vivir mismo de nuestras comunidades.

Los jóvenes no ven en la Iglesia el objeto de su búsqueda y el lugar de respuesta de sus demandas y esperanzas. Se percibe que no es Dios el problema, sino la Iglesia. La Iglesia debe reconocer su dificultad para comunicar con los jóvenes, la carencia de verdaderos proyectos pastorales, el individualismo dominante, la insuficiente toma de conciencia de los carismas y los ministerios, la debilidad teológico-antropológica de ciertas catequesis.

Por parte de muchos jóvenes persiste el temor de que una experiencia en la Iglesia limite su libertad.

Permanecen abiertas las preguntas: ¿Por qué cierta teología y praxis pastoral no "producen» vocaciones, mientras que otras sí? ¿Qué tipo de vocaciones se está generando hoy y qué consecuencias tendrá esto en la vida de la Iglesia?

4.2. En diversos países falta una Pastoral vocacional orgánica (con estructuras y personas) y un Plan vocacional, tanto a nivel nacional como a nivel diocesano y parroquial. Se constata, al mismo tiempo, la abundancia de vocaciones en algunos países del Este.

La dimensión vocacional pertenece al corazón de toda actividad pastoral: catequesis, liturgia, plegaria, caridad, pastoral juvenil, familiar, social, cultural, sanitaria, misionera... El fin es que cada uno de los creyentes responda y desarrolle su vocación cristiana hasta el descubrimiento y asunción de la propia responsabilidad en la Iglesia.

Los consejos pastorales diocesanos y parroquiales, en relación con los Centros vocacionales, son los órganos competentes para procurar y promover responsablemente esta conciencia vocacional en todas las comunidades y en todos los sectores de la pastoral ordinaria.

4.3. La pastoral vocacional tiene la tarea de presentar las etapas fundamentales de un itinerario de fe. El anuncio: en particular con el encuentro de testimonios y de comunidades vive para introducir en la dinámica propia de Jesús: «Venid y ved»; la catequesis: la profundización de la fe y un fuerte alimento espiritual; la propuesta: las iniciativas de llamada personal para permitir a los jóvenes formular un proyecto de vida en seguimiento de Jesús; la guía: por el discernimiento personal y el acompañamiento de quienes está en camino.

4.4. El objetivo cardinal de un plan de pastoral vocacional es el de favorecer la experiencia de Dios, dentro de la Iglesia «comunión». Sólo en el contacto vivo con Jesús Salvador los jóvenes pueden desarrollar la capacidad de comunión, madurar la propia personalidad y decidirse por Él.

La oración, la lectio divina y la experiencia de desierto, los ejercicios espirituales acercan a esta comunión con Dios. La liturgia supone por sí misma una 
llamada. Ella es el lugar privilegiado en el que todo el pueblo de Dios se encuentra de modo visible y se realiza el misterio de la fe.

Cada evangelizador debe tomar conciencia de llegar a convertirse en una «lámpara» vocacional, capaz de suscitar una experiencia religiosa que conduzca a los niños, a los jóvenes, a los adolescentes y a los adultos al contacto con Cristo, en el cual se revelan las vocaciones específicas.

4.5. Los lugares educativos privilegiados para la educación vocacional son la familia, la escuela, la parroquia, y las asociaciones y movimientos.

La experiencia pastoral muestra que la primera manifestación de la vocación nace, en la mayor parte de los casos, en la infancia y la adolescencia. Por esto parece importante recuperar y proponer fórmulas que puedan suscitar, sostener y acompañar esta primera manifestación vocacional, cual se revela en seminarios menores, en preseminarios, en grupos de pre-adolescente y adolescentes, etc...

Como según nos indican los datos culturales el proceso de discernimiento y decisión dura más tiempo y a menudo llega hasta la edad adulta, es necesario un acompañamiento adecuado.

Particular atención hay que prestar a la universidad y a la escuela secundaria, porque éstos son para muchos jóvenes la única y real fuente de experiencia de comunidad cristiana.

4.6. El resurgir del interés por el Evangelio y por una vida dedicada radicalmente a él en la consagración, depende en gran manera del testimonio personal de sacerdotes y religiosas y religiosos felices con su condición. La mayoría de los candidatos a la vida religiosa y al sacerdocio atribuye su vocación a un encuentro tenido con un sacerdote, una religiosa o un religioso. El primer lugar de testimonio es la vida de la Iglesia que se descubre como «comunión» y donde parroquias y realidades asociativas son vistas como comunión de comunidades.

La comunión armoniza los ministerios y carismas de modo que cada uno pueda experimentar la comunidad de Cristo y el mutuo apoyo. Cada vocación tiene necesidad de ayuda, de estima y de promoción de parte de todos.

Un punto delicado e importante es la busca de una relación entre generaciones y entre las diversas experiencias de Iglesia.

Es necesario testimoniar una sincera comunión entre los carismas, los grupos y ministerios, desterrando el espíritu de competencia. Es en cambio importante el conocimiento y la difusión de las diferentes formas de vida consagrada.

El Obispo es garante de la estima hacia todos y de la recíproca acogida. Es necesaria una relación constructiva entre la Iglesia particular y vida consagrada.

4.7. Para que el mundo crea y pueda de nuevo «tener vida», la Iglesia tiene el deber de proveer a los jóvenes de responsables que le acompañen. De gran importancia es, en efecto, la existencia, a todos los niveles de la Iglesia, de los pedagogos, mistagogos, acompañantes, discernientes que se arriesgan a hacer transparente y «contagiar» además, con su testimonio, las estructuras, los planes 
y las estrategias pastorales. En una situación religiosa y cultural que está cambiando rápidamente, es indispensable formar animadores de base: catequistas, párrocos, diáconos, consagrados, obispos y cuidar su formación permanente.

4.8. Los jóvenes tienen el derecho de conocer todas las vocaciones. Se debe hablar tanto de la vocación laical como de la del sacerdocio, del diaconado y de la vida consagrada. Se deben mostrar también los demás ministerios y tareas de la Iglesia.

En la pastoral tradicional el matrimonio, por ejemplo, a menudo no era presentado como una vocación. Hoy es importante considerar el matrimonio como vocación. Sería útil una mayor claridad sobre este tema en la teología pastoral.

4.9. Para ayudar a los jóvenes a superar la indecisión frente a compromisos definitivos se necesita prepararles progresivamente a asumir responsabilidades personales. Para esto es necesario:

-favorecer el descubrimiento de la vida que es el sentirse amado por Dios, de modo que brote la confianza en el Padre que llama y garantiza los medios para la respuesta en la fidelidad;

-madurar la conciencia de que la donación definitiva es una gracia dada por Dios y no sólo sacrificio;

- educar a afrontar la dificultad y la incertidumbre de la decisión como una experiencia privilegiada de la presencia de Dios, a la luz de Cristo crucificado;

- presentar vocaciones de fuerte impacto espiritual que puedan llevar al encuentro personal con Jesús, en ambiente comunitario;

- confiar responsabilidades y tareas adecuadas a las capacidades y la edad;

-animar a las familias a educar a sus hijos para la asunción progresiva de responsabilidades;

-hacer posible el acompañamiento personal cuidando la formación de personas preparadas y espacios de acogida;

-insertar a los jóvenes en grupos en los que se comparta la vida de fe; se ore unidos y se experimente la ayuda fraterna;

-promover una educación progresiva a pequeñas elecciones frente a los valores (gratuidad, constancia, sobriedad, honestidad...).

4.10. Se ha hecho urgente un periodo de discernimiento largo antes de entrar en el seminario o el noviciado, para tener la garantía de que el candidato comprende y aprecia el valor de lo definitivo como «compromiso para toda la vida». Ciertamente el noviciado y el seminario pueden ser entendidos también como un periodo más extendido de discernimiento.

Sobre la formación de los estudiantes de teología, es importante que no sea solamente intelectual, sino unida a una fuerte experiencia espiritual. Igualmente es necesario evitar el riesgo de que estudiantes-seminaristas se transformen en «anti-intelectuales y anti-clericales».

Asimismo es decisiva una relación profunda entre seminarios y diócesis. 
4.11. La pastoral vocacional hoy debe tener una dimensión ecuménica. Todas las vocaciones presentes en cada Iglesia, están comprometidas a asumir unidas el gran desafío de la evangelización para el tercer milenio, dando testimonio de comunión y de fe en Jesucristo, único Salvador del mundo. 